\section{The first year of Infectious Disease Reports}

\author{
David M. Aronoff \\ Division of Infectious Diseases, \\ Department of Internal Medicine and \\ Department of Microbiology and \\ Immunology, University of Michigan, \\ Ann Arbor, MI, USA
}

\section{Text}

Welcome readers to Infectious Disease Reports (IDR). IDR was established in 2009 as an Open Access, peer-reviewed, online-only journal of infectious disease research and practice. I am delighted that over the past year IDR has made significant advances in reaching out "across geographical, cultural, and political barriers to communicate about the latest infectious disease problems and solutions". ${ }^{1}$ It is exciting to note that within our first year IDR has published original studies, review articles, and case reports from $\mathrm{Au}-$ stralia, Brazil, Cuba, Italy, Thailand, Tunisia, Saudi Arabia, Uganda, the UK, and the USA. The first two volumes of IDR have touched upon major problems in our field, including HIV, influenza, Clostridium difficile, neglected tropical diseases, and infections in transplant recipients.

Critical to the success of IDR is the labor of PAGEPress to get our journal indexed online so that our audience of readers and contributors can expand. To date, IDR is present in many online directories, including the Directory of Open Access Journals (DOAJ), Chemical Abstract Service (CAS), IndexCopernicus, Google Scholar, Socolar, and OpenJGate. It is important that IDR has established agreements with companies such as Elsevier (for Scopus), and EBSCO (for EBSCOHost) to include IDR in their products (online subscriptions and CDROMs). Most notably, IDR has been recently catalogued by the National Library of Medicine (NLM; http://www.ncbi.nlm.nih.gov/nlmcata$\log / 101537203)$. This is of great importance because being indexed by NLM is one of the requirements to be included in PubMedCentral and then in PubMed. All of this is helping our internet presence expand. Within the first 8 months of our existence, IDR articles have been read/downloaded approximately 8000 times.

In the coming year it is my sincere hope that the number of submitted manuscripts to IDR continues to increase. We continue to solicit original reports, case reports, literature reviews, and critical analyses/commentaries regarding infectious diseases. New this year, IDR will spearhead efforts to shed light on infections of global importance through the publication of special issues dedicated to single topics. For example, our first special issue will be concerned with infectious diseases and women's health; details available at http:/www.pagepress.org/journals/index.php/i $\mathrm{dr} /$ announcement/view/97. I encourage readers of IDR to contact the journal with ideas of particular concern that would be well suited for a dedicated issue.

The success of IDR also reflects the hard work of the Editorial Board and Managing Editor. The former is a diverse group of infection disease experts from all corners of the planet. Their efforts to solicit reviewers and render critical decisions about our published content have been outstanding and fundamentally important. IDR's Managing Editor, Nicole Pezzolo, continues to tirelessly work to nurture IDR beyond its early stages of development. I look forward to an exciting next year and encourage you to submit your work to IDR.
Correspondence: David M. Aronoff, M.D., 4618 Medical Sciences Building II, 1150 W. Medical Center Drive, Ann Arbor, MI 48109-5623

USA. Phone: $+1.734 .615-3604$

E-mail: daronoff@umich.edu

Key words: Infectious Disease Reports

Received for publication: 26 October 2010 Accepted for publication: 26 October 2010

This work is licensed under a Creative Commons Attribution 3.0 License (by-nc 3.0).

(C) Copyright D. Aronoff, 2010

Licensee PAGEPress, Italy

Infectious Disease Reports 2010; 2:e16

doi:10.4081/idr.2010.e16 